\title{
Clozapine as Add-On Medication in the Maintenance Treatment of Bipolar and Schizoaffective Disorders
}

\author{
A Case Series \\ B. Hummel S. Dittmann A. Forsthoff N. Matzner B. Amann H. Grunze \\ Department of Psychiatry, LMU University Hospital, Munich, Germany
}

Key Words

Bipolar disorder · Schizoaffective disorder · Clozapine

\begin{abstract}
Atypical neuroleptics are increasingly used in the treatment of bipolar and schizoaffective disorders. Currently, numerous controlled short-term studies are available for clozapine, olanzapine, risperidone or quetiapine, but long-term data are still missing. Three patients (2 with bipolar disorder, 1 with schizoaffective disorder) are described who showed a marked reduction of affective symptomatology after clozapine had been added to mood stabilizer pretreatment. The patients were seen once a month before and after the introduction of clozapine for at least 6 months. Treatment response was evaluated using different rating scales (IDS, YMRS; GAF; CGIBP) and the NIMH Life Chart Methodology. All patients showed a marked improvement after the add-on treatment with clozapine had been initiated. Clozapine was tolerated well with only transient and moderate weight gain and fatigue as only side effects. This case series underlines the safety and efficacy of clozapine as add-on medication in the treatment of bipolar and schizoaffec-
\end{abstract} tive disorders.

Copyright $@ 2002$ S. Karger AG, Basel

\begin{tabular}{ll}
\hline KARGER & ( ) 2002 S. Karger AG, Basel \\
0302-282X/02/0455-0037\$18.50/0 \\
$\begin{array}{l}\text { Fax +4161306 12 34 } \\
\begin{array}{l}\text { E-Mail karger@karger.ch } \\
\text { www.karger.com }\end{array}\end{array}$ & $\begin{array}{l}\text { Accessible online at: } \\
\text { www.karger.com/journals/nps }\end{array}$
\end{tabular}

\section{Introduction}

The management of bipolar and schizoaffective disorders is a challenging task for clinicians. Although several mood stabilizers, e.g., lithium, valproic acid or carbamazepine, are available, there is still a number of patients unresponsive to either a monotherapy or even a combination treatment [1]. Lithium nonresponse is estimated at $33 \%$ in patients with 'classical' bipolar disorder [2] and thought to be even higher in patients with mixed episodes or rapid cycling [3, 4]. Additionally, manic patients are still treated with typical antipsychotics in the acute phase and even as maintenance treatment, despite the high risk of tardive dyskinesia [5,6]. A longitudinal study could also demonstrate that the long-term use of neuroleptic agents was associated with a cycle acceleration and thus a worsening of the long-term course of the illness [7]. In another double-blind study in which lithium monotherapy was compared to the combination treatment of lithium and flupentixol for 2 years, patients randomized to combination treatment suffered from more depressive episodes while the frequency of manic episodes was not significantly different [8]. Atypical antipsychotics such as clozapine, olanzapine, risperidone or quetiapine are considered as relatively safe alternatives used as add-on med- 
ication in the maintenance treatment of bipolar and schizoaffective disorders [9]. Hints at efficacy of clozapine in schizoaffective [10-12] and bipolar disorders [13-15] were reported by several authors. However, controlled trials of clozapine in maintenance treatment are still missing. This might be not only due to the fact that clozapine has the side effect of agranulocytosis, but also to a lack of commercial interest in this relatively old drug.

Here we report on 3 well-characterized and followedup patients in whom clozapine as add-on medication led to complete remission of symptoms.

\section{Case Reports}

\section{Case 1}

$\mathrm{Mr}$. B. is a 34-year-old patient with bipolar I disorder and a rapid cycling course. His first depressive episode occurred at the age of 13 , the first mania at the age of 15 . Shortly after he developed a rapid cycling course with mood switches every 14 days and without any symptom-free interval. Combination treatment of lithium and carbamazepine led to a complete remission of symptoms for 15 years. Then the ultrarapid cycling reoccurred, and additionally he developed comorbid kleptomania, panic attacks, binge-eating disorder and marihuana abuse. Attempts to stabilize his mood with e.g. valproate, lamotrigine or different antidepressants failed. He was on a combination treatment with lithium, valproate, lamotrigine and paroxetine without any change of his rapid cycling course when he first visited our outpatient clinic. Both his depressive and manic episodes ranged from moderate to severe. Especially in his depressed phases, he had strong suicidal ideations. We decided to taper lithium, lamotrigine and paroxetine gradually and to start treatment with clozapine. After the titration phase, the daily dose of clozapine was $250 \mathrm{mg}$. In the following 6 months, his manias subsided completely, and the depressive episodes became fewer and milder. With the later addition of $\omega-3$ fatty acids it was possible to manage also his depressive episodes. The combination treatment of valproate, clozapine and $\omega-3$ fatty acids was shown to be safe and effective. The only side effects were weight gain, fatigue and mild diarrhea, which all subsided after some weeks of treatment. Controlling his eating habits, the patient now even lost $14 \mathrm{~kg}$ of weight and had no manias for 1 year and no severe depressions for several months (fig. 1). Comorbid symptoms and suicidal ideations are no longer present.

\section{Case 2}

Mr. R. is a 34-year-old patient with bipolar I disorder. His first depressive episode with psychotic symptoms occurred at the age of 19. During the course of his illness, he had many very severe dysphoric manias, sometimes with mood-incongruent psychotic features that always led to hospitalization and which were mostly treated with the combination of lithium and carbamazepine as maintenance treatment and haloperidol in the acute phase. During the 3 years before he visited our outpatient clinic, he also received haloperidol as a maintenance treatment. This led to an increase in the rate and severity of the depressive episodes. We first put Mr. R. on the combination of lamotrigine and clozapine, but a severe manic episode in which two hospitalizations were necessary led to the substitution of lamotrigine with valproate. The daily dosage of clozapine is now $200 \mathrm{mg}$ and that of valproate $1,500 \mathrm{mg}$. Mr. R. has been taking clozapine in combination with valproate for 1 year now, and no recurrence has been noted so far (fig. 2). Side effects are not present. Even with the combination treatment of valproate and clozapine, $\mathrm{Mr}$. $\mathrm{R}$ has lost $10 \mathrm{~kg}$ of weight since he stopped taking lithium, carbamazepine and haloperidol as maintenance treatment. He is also able to exercise, which he said he had not been able to do for years due to severe fatigue.

\section{Case 3}

Ms. F. is a 23-year-old woman suffering from schizoaffective disorder. Besides her mood episodes, incongruent psychotic features like paranoid delusions and ideas of reference were the prominent symptoms, independently from mood deflections. Her first mania occurred at the age of 20. At that time delusions were also prominent symptoms. The treatment with risperidone $4 \mathrm{mg}$ /day led to a fast remission. After discontinuing the medication, she experienced another exacerbation of mania which again led to hospitalization. The treatment with valproate $1,500 \mathrm{mg} /$ day led to a fast stabilization, but still mild mood swings occurred. Shortly after her release, Ms. F. had to be hospitalized again due to another manic episode. Besides manic symptoms, psychotic symptoms were again prominent features. In addition to valproate, haloperidol was necessary to treat the psychotic symptoms. After the acute symptomatology had faded, we tried to replace haloperidol with risperidone to continue with the combination of valpraote and risperidone as maintenance treatment. However, another exacerbation of the manic and psychotic symptoms occurred. A trial with olanzapine was also unsuccessful, due to severe side effects (fatigue, depressive symptoms, difficulties to concentrate). We finally switched to a combination treatment of valproate $1,300 \mathrm{mg} /$ day and clozapine $100 \mathrm{mg} /$ day. During the titration phase, Ms. F. suffered from fatigue; no other side effects occurred. For the last 9 months, Ms. F. has had no more mood symptoms and has tolerated the drugs without side effects (fig. 3).

\section{Discussion}

The 3 cases described here show that clozapine is a safe and effective add-on medication in bipolar and schizoaffective disorder. All patients tolerated it well. No blood count changes have occurred yet. This case series is in line with other reports and trials which describe clozapine as an effective treatment for bipolar and schizoaffective patients $[9,16]$. In the 2 patients in whom also incongruent psychotic features occurred, clozapine was an effective antipsychotic as well. Keeping the risk of tardive dyskinesia in mind and knowing that even nowadays many bipolar patients still receive long-term treatment with typical antipsychotics, clozapine seems to be an alternative of choice. There is also the risk of inducing depressive episodes by putting patients on typical antipsychotics. Given that clozapine might not have strong antidepressant properties, it seems not to induce depression. 


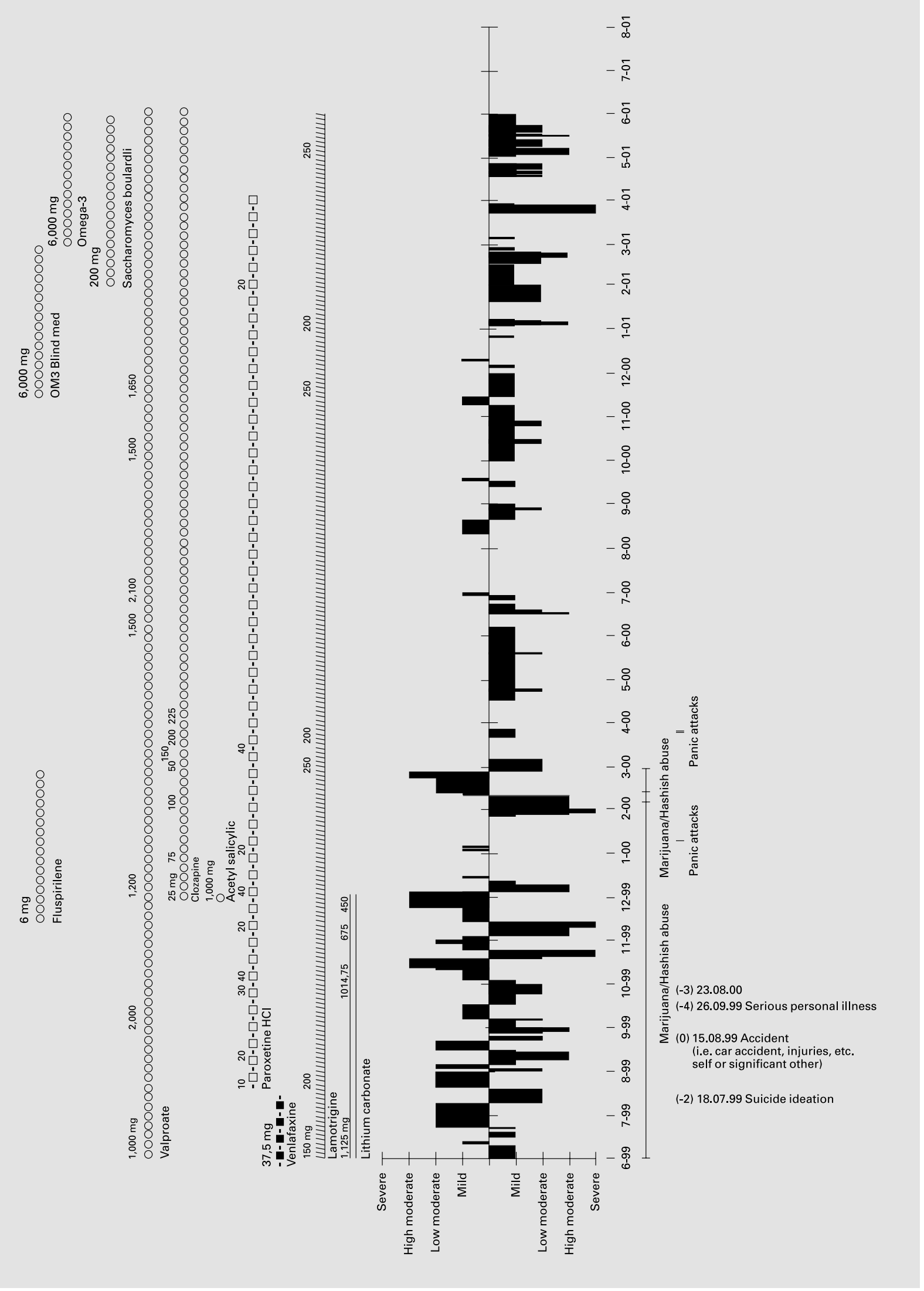




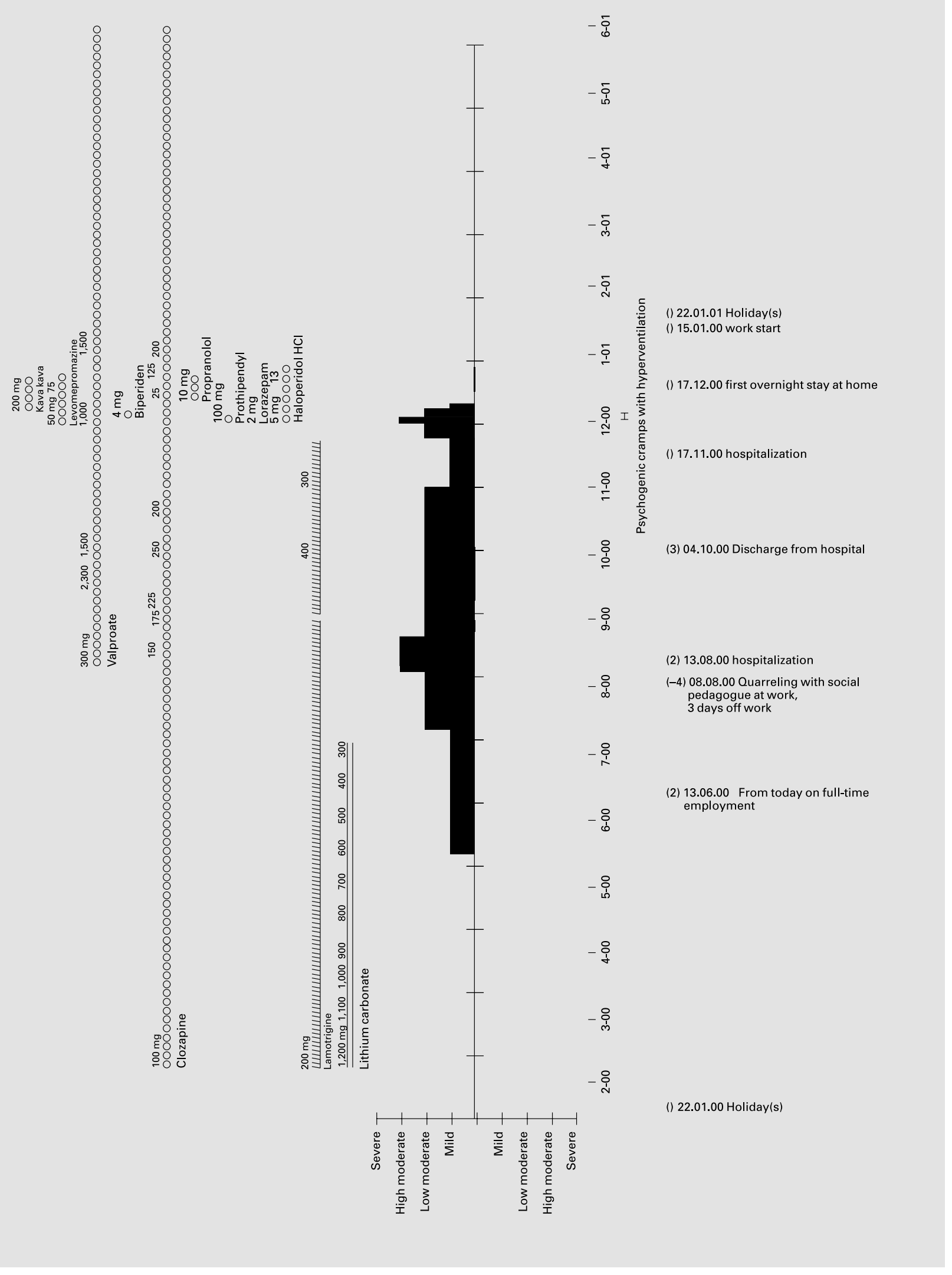




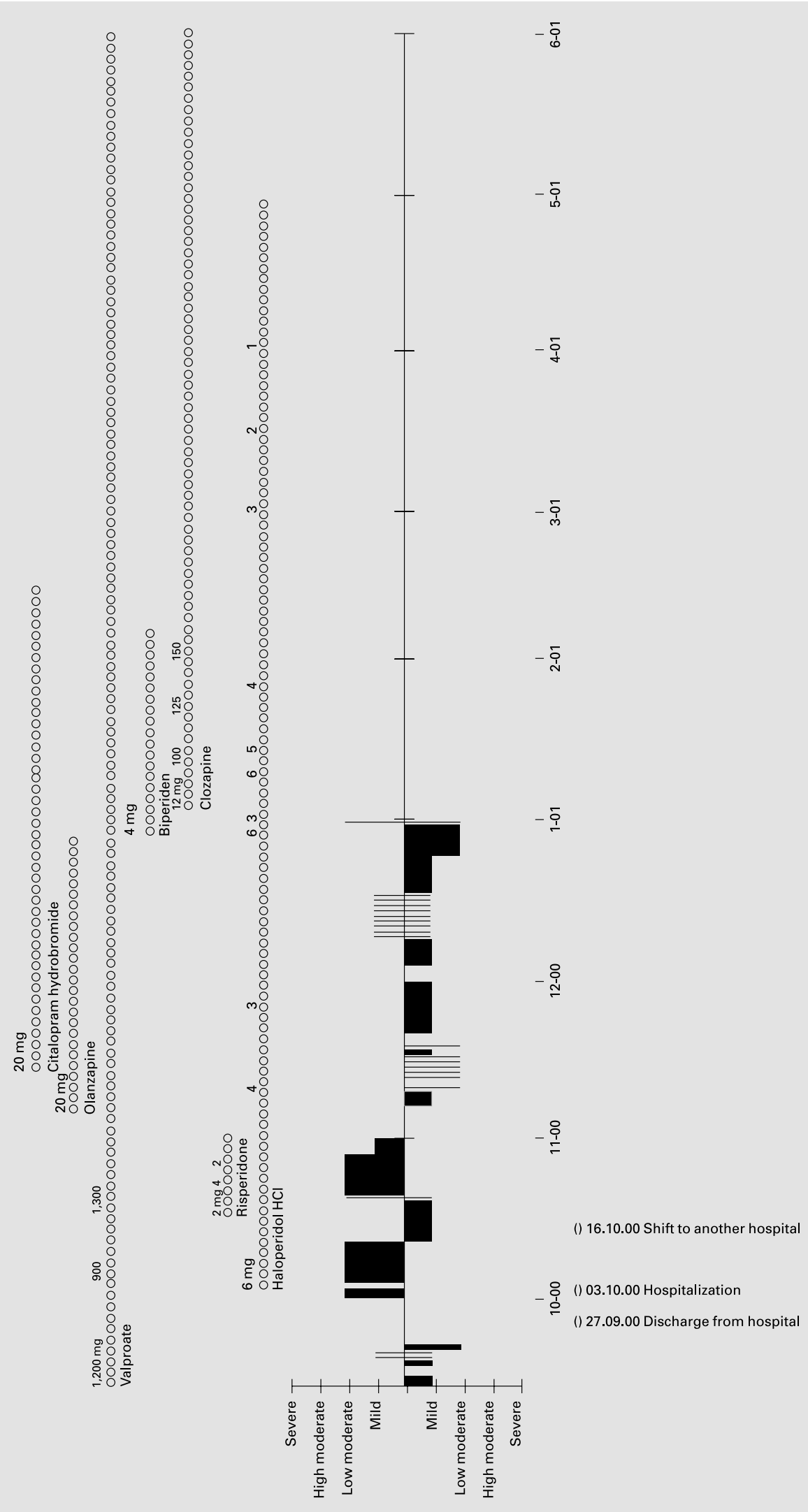


In the cases described here, the only side effects which occurred were fatigue and weight gain during the titration phase. Later on, tolerability was no longer a problem. Interestingly, 2 patients who suffered from severe weight gain before they got clozapine and during the titration phase even lost more than $10 \mathrm{~kg}$ during the continuation treatment with the combination of clozapine and valproate. In summary, this case series is another hint at the effectiveness and safety of clozapine in the treatment of bipolar and schizoaffective disorders, but still more controlled studies are necessary to further investigate the use of clozapine and other atypical antipsychotics.

\section{References}

1 Banov MD, Zarate CA Jr, Tohen M, Scialabba D, Wines JD Jr, Kolbrener M, Kim JW, Cole JO: Clozapine therapy in refractory affective disorders: Polarity predicts response in longterm follow-up. J Clin Psychiatry 1994;55: 295-300.

2 Prien RF, Gelenberg AJ: Alternatives to lithium for preventive treatment of bipolar disorder. Am J Psychiatry 1989;146:840-848.

3 Dunner DL, Patrick V, Fieve RR: Rapid cycling manic depressive patients. Compr Psychiatry 1977; 18:561-566.

4 McElroy SL, Keck PE, Pope HG, Hudson JI, Faedda GL, Swann AC: Clinical and research implications of the diagnosis of dysphoric or mixed mania or hypomania. Am J Psychiatry 1992;149:1633-1644.

5 Kane JM: The role of neuroleptics in manicdepressive illness. J Clin Psychiatry 1988 ; 49(suppl):S12-S14.

6 McElroy SL, Keck PE, Strakowski SM: Mania, psychosis, and antipsychotics. J Clin Psychiatry 1996;57(suppl 3):S14-S26.
7 Kukopulos A, Reginaldi D, Laddomada P, Floris G, Serra G, Tondo L: Course of the manicdepressive cycle and changes caused by treatment. Pharmakopsychiatr Neuropsychopharmakol 1980;13:156-167.

8 Ahlfors UG, Baastrup PC, Dencker SJ, Elgen $\mathrm{K}$, Lingjaerde O, Pedersen V, Schou M, Aaskoven O: Flupenthixol decanoate in recurrent manic-depressive illness: A comparison with lithium. Acta Psychiatr Scand 1981;64:226237.

9 Ghaemi SN: New treatments for bipolar disorder: The role of atypical neuroleptic agents. J Clin Psychiatry 2000;61(suppl 14):S33-S42.

10 Owen RR Jr, Beake BJ, Marby D, Dessain EC, Cole JO: Response to clozapine in chronic psychotic patients. Psychopharmacol Bull 1989; 25:253-256.

11 Leppig M, Bosch B, Naber D, Hippius H: Clozapine in the treatment of 121 out-patients. Psychopharmacology (Berl) 1989;99(suppl): S77-S79.
12 Naber D, Leppig M, Grohmann R, Hippius H: Efficacy and adverse effects of clozapine in the treatment of schizophrenia and tardive dyskinesia - A retrospective study of 387 patients. Psychopharmacology (Berl) 1989;99(suppl): S73-S76.

13 Tohen M, Zarate CA: Antipsychotic agents and bipolar disorder. J Clin Psychiatry 1998; 59(suppl 1):S38-S48.

14 Zarate CA, Tohen M, Baldessarini RJ: Clozapine in severe mood disorders. J Clin Psychiatry 1995;56:411-417.

15 Zarate CA, Tohen M, Banov MD, Weiss MK, Cole JO: Is clozapine a mood stabilizer? J Clin Psychiatry 1995;56:108-112.

16 Ciapparelli A, Dell'Osso L, Pini S, Chiavacci MC, Fenzi M, Cassano GB: Clozapine for treatment-refractory schizophrenia, schizoaffective disorder, and psychotic bipolar disorder: A 24-month naturalistic study. J Clin Psychiatry 2000;61:329-334. 